\title{
Mushroom diversity in the Biligiri rangana hills of Karnataka (India)
}

\section{Akash, N. Earanna* and S. Subramanya ${ }^{1}$}

Department of Biotechnology, University of Agricultural Sciences, Bangalore-560065 (Karnataka), INDIA ${ }^{1}$ Department of Post Harvest Technology,University of Agricultural Sciences, Bangalore-560065 (Karnataka), INDIA *Corresponding author. E -mail. earanna7@gmail.com

Received: August 31, 2016; Revised received: February 19, 2017; Accepted: July 8, 2017

Abstract: Evergreen forests of Biligiri rangana hills (BR hills) spread over an area of 540 sq. KM over eastern most edge of Western Ghats in Karnataka. Climatic conditions are more favorable for establishment of mushrooms and complete their life cycle. In this study, fourteen mushroom species were collected from BR hills regionduringmonsoon (June through September 2013) with the help of Solega tribe inhabited the region since many years. Of the fourteen mushrooms, two mushrooms were identified as Ganoderma lucidum and Polyporous flabelliformis based on their phenotypic characters. The other 12 mushrooms were identified by ITS (Internal Transcribed spacer)region sequence homology as Termitomyces sp. (BRM-3)., Auricularia delicate (BRM-4), Termitomyces microcarpus (BRM -5), Amanita sp. (BRM-6), Podoscypha petalodes (BRM-7), Agaricaceae sp. (BRM-8), Macrolepiota sp.(BRM-9), Calvatia holothurioides (BRM-10), Gymnopillus crociphyllus (BRM-11), Coprinus comatus (BRM-12), Gyrodontium sacchari (BRM-13) and Clitocybeafffellea (BRM-14). Among the fourteen mushrooms, three species viz., Termitomyces species, Auricularia delicate and Termitomyces microcarpus were edible. The others were non edible/ poisonous species. This study reports the diverse mushroom species as addition to biodiversity at BR hills.

Keywords: Biligiri rangana hills, Documentation, ITS region, Mushroom diversity

\section{INTRODUCTION}

BR Hills are located in between $11^{\circ} 47^{\prime}-12^{\circ} 9^{\prime} \mathrm{N}$ and $77^{\circ} 0^{\prime}-77^{\circ} 16^{\prime} \mathrm{E}$. The ridges of hills run in the northsouth direction. It is a projection of Western Ghats in a north-eastern direction and meets the hills of Eastern Ghats at $78^{\circ} \mathrm{E}$ situated in Yelandur and Kollegal Taluks of Chamaraja nagar district of south-eastern part of Karnataka (Sreenivasan and Prashanth, 2005). There is a variation in mean temperature ranging from 9 to 16 ${ }^{\circ} \mathrm{C}$ minimum and 20 to $38{ }^{\circ} \mathrm{C}$ maximum. The region receives $600 \mathrm{~mm}$ annual rainfall at the base and 3000 $\mathrm{mm}$ at top of the hills (Gireesha and Raju, 2013). The wide range of climatic conditions along with altitude made an ecosystem congenial for bio diversity. The Solega tribes inhabited the region over hundreds of years are nature worshippers and mainly dependent on forest products for their livelihood. Mushrooms are sources of good quality protein, vitamins and minerals. They are low in calorie with negligible starch, sugars and fats. In addition, many edible and non-edible mushrooms have been used for medicinal purposes (Wasser and Weis, 1999; Hobbs, 1995). Mushrooms appear during rainy season when the soil is moist and weather conditions are cool and humid. Therefore, mushroom hunting in such seasons is essential.

Mushrooms can be identified based on their morphological characters such as shape, size, texture, colour and odour of the fruiting body. The microscopic characters viz., spore size, spore shape, basidium structure etc. Despite the above, use of molecular tools to identity wild mushrooms have become quick and reliable methods in recent years. The ribosomal RNA genes (rDNA) of fungi are located on a single chromosome and are present as repeated subunits of a tandem array of transcribed and non-transcribed stretches of DNA, which appeared highly conserved. The ITS region/ 18S rRNA gene sequence are the most widely used techniques in molecular phylogenetics to identify the mushrooms up to species level (Rajaratnam and Thiagarajan, 2012). Victor et al. (2012) Identified $18 \mathrm{Ter}$ mitomyces species collected from 2 states (Ondo and Ekiti) of Nigeria using ITS region and compared with existing sequences in NCBI Gen Bank. Several workers from elsewhere reported molecular identification of mushrooms using ITS 1 and ITS 2 primers (Oyetayo, 2012; Sudip et al., 2013). The BR hills as reserve forest area, various flora, animals and birds diversity was reported with help of forest and ecology department. This study, reports the mushroom diversity of the protected area.

\section{MATERIALS AND METHODS}

Collection and documentation of mushrooms: Mushrooms were collected during rainy season from June to September 2013 with the help of tribal (Solega) 
people in the agricultural field bunds, forest anddomicile area of the Soligas, in a paper bags and were named as BRM-1, BRM-2, BRM-3, BRM-4, BRM-5, BRM-5, BRM-7, BRM-8,

BRM-9, BRM-10, BRM-11，BRM-12，BRM-13and BRM-14(BRM=Biligiri Rangana hills Mushroom).Field information for all the mushrooms during collection was recorded.

\section{Molecular characterization:}

Genomic DNA Isolation: Total genomic DNA from cap/ stipe tissue of the mushrooms was extracted using CTAB method (Sambrook et al., 1989). The DNA concentration was measured using Nanodrop (Eppendorff) and then PCR amplification was carried out in $40 \mu 1$ reaction mixture containing $4.0 \mu 1$ of $10 \mathrm{X}$ PCR Taq-Buffer, $4.0 \mu \mathrm{l}$ of $10 \mathrm{mM}$ dNTP's mix, $2.0 \mu \mathrm{l}$ of ITS primers (ITS15'TCCGTAGGTGAACCTGCGG3'and ITS4-5' TCCTCCGCTTATTGATATGC 3', $0.6 \mu l$ of Taq. DNA polymerase, $2.0 \mu \mathrm{l}$ of Template DNA ( $\sim 50 \mathrm{ng})$ and 27.4 $\mu \mathrm{l}$ of sterile distilled water.

PCR amplification: The PCR reaction was carried out in a Thermal Cycler (Applied Bio systems) programmed as initial denaturation at $96^{\circ} \mathrm{C}$ for $3 \mathrm{~min}, 40$ cycles of denaturation of $94^{\circ} \mathrm{C}$ for $1 \mathrm{~min}$, annealing at $60^{\circ} \mathrm{C}$ for $30 \mathrm{sec}$ and extension at $72^{\circ} \mathrm{C}$ for $1 \mathrm{~min}$ and final extension at $72^{\circ}$ $\mathrm{C}$ for $10 \mathrm{~min}$. The amplified products were separated by agarose gel electrophoresis. The gel was visualized under UV light and documented using Alpha Innotech Gel documentation unit. The amplified product was eluted using Gene JET ${ }^{\text {TM }}$ Gel Extraction Kit (Thermo Scientific) following manufacturer protocol.

Cloning, transformation and sequencing: The eluted product was cloned into pTZ57R/T cloning vector using InsT/A clone PCR product cloning kit [MBI, Fermentas Life Sciences, USA (\#K1214)] after determining the appropriate vector: insert ratios (Sambrook et al.,1989). The ligation reaction was performed in a $10 \mu \mathrm{l}$ reaction volume at $16^{\circ} \mathrm{C}$ overnight. The ligated product was transformed in to Escherichia coli (DH5 $\alpha$ ) cells using heat shock method (Sambrook et al., 1989) and plated on Luria Berton (LB) agar medium containing antibiotic (ampicillin, $100 \mu \mathrm{g} / \mathrm{ml}$ ). The recombinant clones were initially screened for blue white selection, followed by colony PCR using M13 forward and reverse primers (Sambrook et al., 1989). Then the transformed colony was multiplied in LB broth containing $100 \mu$ lampicillin for overnight and the recombinant plasmid was isolated using GenElute ${ }^{\mathrm{TM}} \mathrm{HP}$ Plasmid MiniPrep Kit (Sigma, USA) following the manufactures protocol. The isolated plasmid was sequenced at Sci Genome Labs Private Ltd. Kerala, INDIA using M13 forward and reverses primers.

Sequence analysis and homology search: Sequence results were analyzed with Vec Screen online software from National Centre for Biotechnology Information (NCBI) for removing the vector contamination. Forward and reverse primer sequences were checked against each other by generating the reverse complement of the "reverse" sequence using Fast PCR Professional (Experimental test version 5. 0. 83) and aligning it with the "forward" sequence with the help of CLUSTAL W Multiple Sequence Alignment Programme using online software SDSC Biology Workbench (San Diego Supercomputer Center). The full-length gene homology search was performed with blast programme of NCBI (Altschul et al., 1990).

\section{RESULTS AND DISCUSSION}

In the present study two mushrooms (BRM-1 and BRM-2) collected in the month of August 2012 were identified based on phenotypic characters. The BRM-1 bearing robust corky fruiting body was found growing on the hard wood. The pileus was reddish brown colour and border surrounded by white colour, embricate in shape. The diameter of cap was $14 \mathrm{~cm}$ and stipiate polypore (Table, 1 and Fig.1). The other mushroom (BRM-2) vernacularly known as Maraanabe was found growing on dead wood. Sporophore was stipiate, pileus was deep brown colour with depression at the center (Fig.2). Basidiaclavate, gills were absent, scattered growth habit. After verifying these characters with the keys described for classification of polyphores by Bakshi (1971), they were identified as Ganoderma lucidum (BRM-1) and Polyporus flabelliformis,(BRM-2).

Molecular identification:Molecular identification was done for other 12 mushrooms using ITS region sequence. The gene sequence analysis (BLAST) was made with the sequences available at NCBI Gen Bank. The Fig.3 represents the full length homology search of BRM-13 (Gyrodontium sacchari), (BLAST search of other mushrooms not shown). The sequence length (base pair) of 12 mushrooms was given in Table 2.

BRM-3: Vernacularly known as Doddaanabe due to its robust fruiting body, scattered growth habit (Fig. 4a). Thepileus up lifted creamy white, $12 \mathrm{~cm}$ in diameter. The stipe tapered downward, central and $9 \mathrm{~cm}$ in length. Gills were free, annulus and rhizoids present. The ITS region with 734 bp sequence showed 99 per cent homology with Termitomyces sp.

BRM-4: Vernacular name of this mushroom was Mavuanabe. Because of its jelly texture it was known as jelly fungi. Fruiting body was brown in colour(Fig.4b). Amplified ITS region (604bp) showed 99 per cent homology with Auricularia delicata.

BRM-5: It is a mini edible mushroom and locally named as Kolianabe, collected near termite nests. Fruiting body was white colour with plane pileus (Fig. 4c). Stipe present in central position. Gills present and annulus absent. The blast analysis of $603 \mathrm{bp}$ sequence showed $95 \%$ homology with Termitomyces microcarpus.

BRM-6: Pileus was creamy white, convex shaped (Fig. 4d). Stipe tapered upward and central in position, length was $15 \mathrm{~cm}$. Scales present on pileus and stipe surfaces. Gills were adnexed, annulus present. The 
Akash, D. et al. / J. Appl. \& Nat. Sci. 9 (3): 1381 -1387 (2017)

Table 1. Field information of wild mushrooms collected from Biligirirangana hills.

\begin{tabular}{llllll}
\hline Sl. & Mushrooms & Vernacular Name & Date of collection & Edibility & Habitat \\
No & collected & & Medicinal & Tree \\
\hline 1 & BRM-1 & Dodamaraanabe & $09 / 08 / 2013$ & Non edible & Wood \\
2 & BRM-2 & Mara anabe & $26 / 08 / 2013$ & Edible & Soil \\
3 & BRM-3 & Dodaanabe & $26 / 08 / 2013$ & Edible & Tree \\
4 & BRM-4 & Mavuanabe & $20 / 07 / 2013$ & Edible & Soil \\
5 & BRM-5 & Kolianabe & $05 / 09 / 2013$ & Poisonous & Humus \\
6 & BRM-6 & Not Known & $23 / 06 / 2013$ & Non edible & Soil \\
7 & BRM-7 & Not Known & $05 / 09 / 2013$ & Non edible & Soil \\
8 & BRM-8 & Huchanabe & $23 / 06 / 2013$ & Non edible & Soil \\
9 & BRM-9 & Not Known & $26 / 08 / 2013$ & Non edible & Soil \\
10 & BRM-10 & Not Known & $09 / 08 / 2013$ & Non edible & Dead wood \\
11 & BRM-11 & Not Known & $23 / 06 / 2013$ & Non edible & Soil \\
12 & BRM-12 & Not Known & $09 / 08 / 2013$ & Non edible & Dead wood \\
13 & BRM-13 & Haladianabe & $09 / 08 / 2013$ & Non edible & Soil \\
14 & BRM-14 & Kotesutthuanabe & $05 / 09 / 2013$ & &
\end{tabular}

$\mathrm{BRM}=$ BiligiriRanganaHill Mushroom

Table 2. List of Mushroom species identified using ITS gene sequencing.

\begin{tabular}{lllll}
\hline S. N. & Mushroom sample & Mushrooms identified & Size of amplified product (bp) & Homology (\%) \\
\hline 1 & BRM-3 & Termitomyces sp. & 734 & 99 \\
2 & BRM-4 & Auricularia delicata & 604 & 99 \\
3 & BRM-5 & Termitomyces microcarpus & 603 & 95 \\
4 & BRM-6 & Amanita sp. & 614 & 99 \\
5 & BRM-7 & Podoscypha petalodes & 693 & 99 \\
6 & BRM-8 & Agaricaceae sp. & 729 & 99 \\
7 & BRM-9 & Macrolepiota sp. & 726 & 98 \\
8 & BRM-10 & Calvatiaholo thurioides & 732 & 95 \\
9 & BRM-11 & Gymnopilus crociphyllus & 542 & 99 \\
10 & BRM-12 & Coprinus comatus & 822 & 99 \\
11 & BRM-13 & Gyrodontium sacchari & 736 & 99 \\
12 & BRM-14 & Clitocybeaff. fellea & 736 & 99 \\
\hline
\end{tabular}

$\mathrm{BRM}=$ BiligiriRanganaHill Mushroom; $\mathrm{b} p=$ base pair

sequence of the ITS region (614 bp) showed $99 \%$ homology to Amanita sp. available at NCBI Gen Bank.

BRM-7: ThePileus creamy, petaloid with leathery texture (Fig. 4e). Stipe, gills and annulus were absent. The ITS sequence (693bp) showed 99 percent homology with Podoscyphapetalodes.

BRM-8: Themushroom was vernacularly known as Huchanabe in Kannada.Pileus creamy white, convex shaped (Fig. 4f). Stipebulged at the bottom $12 \mathrm{~cm}$ length. Gills and annulus present. The sequence of ITS region (729bp) showed 99 per cent homology with Agaricaceae sp.

BRM-9: Large fruiting body with soft and crispy texture; scattered growth habit. Convex shaped pileuswith prominent scales on surface (Fig. 4g).Stipe enlarged at the bottom.Gills present and annulus absent. The sequence homology (726bp) of blast analysis showed 98 per cent homology with Macrolepiota sp.

BRM-10: Orangecoloured fruiting body with cone shape (Fig. 4h).Scattered growth habit; rhizoids present. Gills absent, soft textured. Sequence analysis ofITS region (732bp) showed 95 per cent homology with Calvatiaholo thurioides available at NCBI Gen Bank.

BRM-11: Itwas found on dead wood (Fig. 4i).Pileus was yellow and convex shaped. Stipe tapered upward, $4 \mathrm{~cm}$
long.Gills present, annulus absent. Fruit body texture was soft. The analysis of amplified ITS sequence (542bp) showed 99 per cent homology with Gymnopilus crociphyllus.

BRM-12: Soft textured white mushroom,convex shaped pileus (Fig. 4j) with $9 \mathrm{~cm}$ diameter. Stipe was club shaped $14 \mathrm{~cm}$ long.Gills and annulus present. The ITS region sequence (822bp) in blast analysis showed 99 per cent homology with Coprinus comatus.

BRM-13: Vernacularname of the mushroom wasHaladianabedue to itsyellowish tinge (Fig. 4k). Pileus and stipe absent, corky textured, teeth present below the surface. The sequence (736bp) showed 99 per cent homology with Gyrodontium sacchari.

BRM-14: The mushroom was known as Kotesuthuanabe. Found in clusters, Pale brown colored pileus, stipe and annulus absent (Fig. 41).Gills decurrent with soft texture. ITS region sequence of 736 bp showed 99 per cent homology with Clitocybeaff fellea.

Mushroom hunting is an art which needs skill and experience to differentiate edible mushroom from poisonous species as there are no pool proof methods available so far. However, by knowing the species after taxonomic identification, one can ensure precise identity. Therefore, 


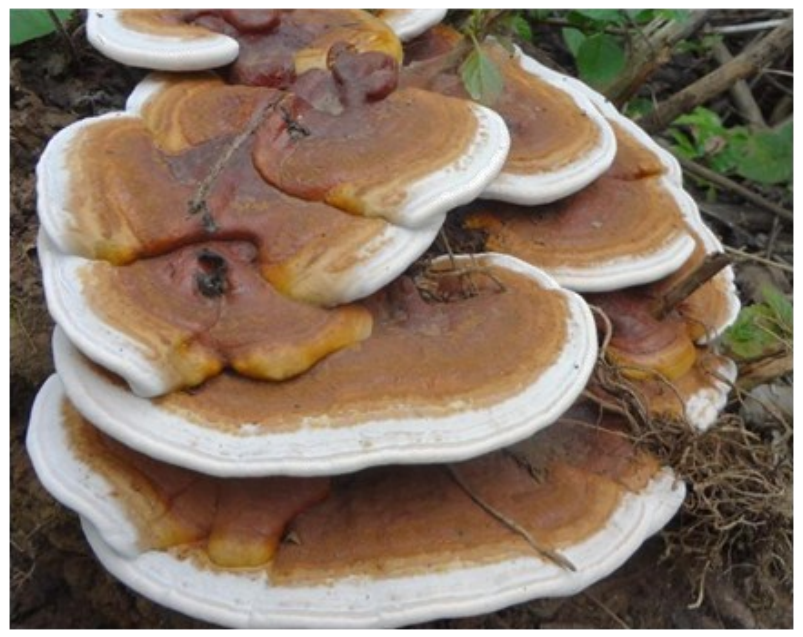

Fig.1. Ganoderma lucidum (BRM-1)

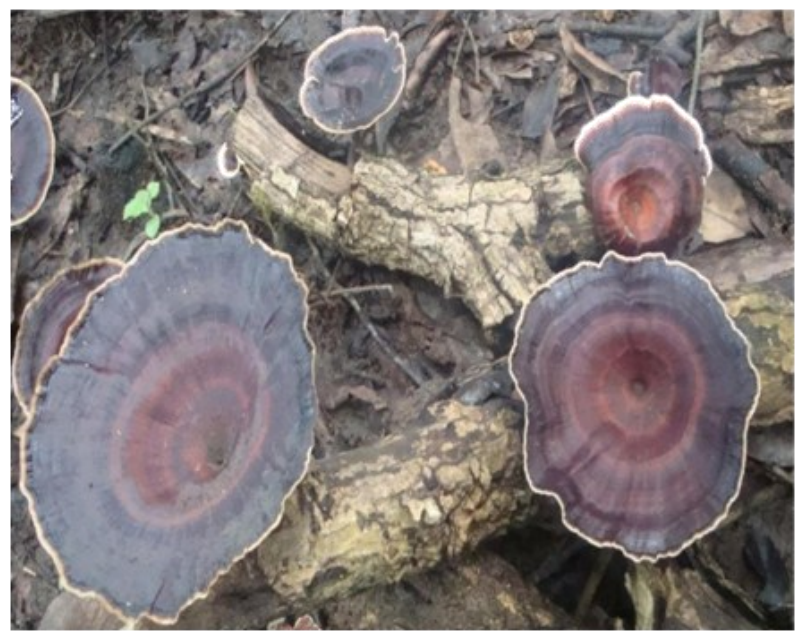

Fig.2. Polyporus flabelliformis (BRM-2) scientific identification is very much essential in this context. Mushroom hunting is a never ending process as occurrence of different species depends on season, climate, habitat and rainfall (Arora, 1986). In this study, totally fourteen species of mushrooms were documented from BR Hills with the help of Forest Department and Solegatribe inhabiting the area. The observations recorded for phenotypic characters of pileus, stipe, gills arrangement and microscopic characters like spore shape, color, the two mushrooms,BMR-1 and BMR-2 were identified as Ganoderma lucidum and Polyporus flabelliformis, respectively (Bakshi, 1971). In classical taxonomy, identification of mushrooms is being done on phenotypic characters (Arora, 1986; Bhatt et al., 1995). Meera and Veena, (2012) collected 45 species of mushrooms and identified by morphological characters from Kodagu district of Western Ghats, Karnataka.

Classical taxonomy depends on phenotypic characters, which some time leads to confusion between taxonomists and it may not useful for identification of younger fruit bodies. In such circumstances, the molecular identification using 18S rRNA gene/ITS region sequence is essential. In molecular taxonomy, the gene encoding for 16SrRNA in prokaryotes and 18S rRNA/ITS in eukaryotes are most widely used (Gross et al. 2001). The small subunit (30S) ribosomal RNA (SSU rRNA) genes sequence have been extensively used for sequence based evolutionary analysis because, they are universally distributed, functionally constant, sufficiently conserved and have adequate length and therefore, providing a view of evolution encompassing all living organisms (Madigan et al., 2009).

The 18S rRNA/ ITS flanking sequence are highly conserved in eukaryotes. Primer developed for flanking sequence of $18 \mathrm{~S}$ r RNA/ ITS can be used as a universal

GTCAGAGGTGAAATTCTTGGATTTACTGAAGACTAACTACTGCGAAAGCATTT-

GCCAAGGATGTTTTCATTAATCAAGAACGAAGGTTAGGGGATCGAAAACGATCAGATACCGTTGTAGTCTTAACA GTAAACTATGCCGACTAGGGATCGGGCAATCTCTTTTTGATGTGTTGCTCGGCACCTTACGAGAAATCAAAGTCTT TGGGTTCTGGGGGGAGTATGGTCGCAAGGCTGAAACTTAAAGGAATTGACGGAAGGGCACCACCAGGAGTGGAG CCTGCGGCTTAATTTGACTCAACACGGGGAAACTCACCAGGTCCAGACATGACTAGGATTGACAGATTGATAGCT CTTTCATGATTTTATGGGTGGTGGTGCATGGCCGTTCTTAGTTGGTGGAGTGATTTGTCTGGTTATCCGATAACGA ACGAGACCTTAACCTGCTAAATAGCCAGGCTGGCTTTCGCTGGTCGCCGGCTTCTTAGAGGGACTGTCAGCGTCT AGCTGACGGAAGTTTGAGGCAATAACAGGTCTGTGATGCCCTTAGATGTTCTGGGCCGCACGCGCGCTACACTGA CAGAGCCAGCGAGTTCTTTTTCCTTGGCCGGAAGGTCTGGGTAATCTTGTGAAACTCTGTCGTGCTGGGGATAGA GCATTGCAATTATTGCTCTTCAACGAGGAATTCCTAGTAAGCGTGAGTCATCAGCTCGCGTTGATTACGTCCCTGC

\begin{tabular}{|c|c|c|c|c|c|c|c|}
\hline \multicolumn{8}{|c|}{ 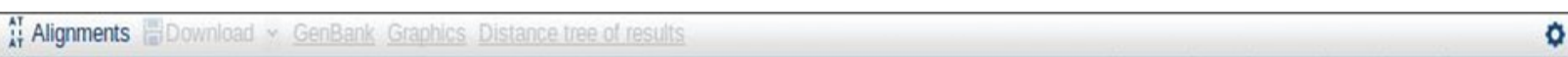 } \\
\hline & Description & $\begin{array}{l}\text { Max } \\
\text { score }\end{array}$ & $\begin{array}{l}\text { Total } \\
\text { score }\end{array}$ & $\begin{array}{l}\text { Query } \\
\text { cover }\end{array}$ & $\begin{array}{c}E \\
\text { value }\end{array}$ & Ident & Accession \\
\hline Q & Gyrodontium sacchari MUCL:40589 18S small subunit ribosomal RNA qene, partial sequence & 1317 & 1317 & $99 \%$ & 0.0 & $99 \%$ & $\underline{\text { GU187632.1 }}$ \\
\hline ○ & Serpula incrassata DAOM 17059018 S small subunit ribosomal RNA gene, partial sequence & 1290 & 1290 & $99 \%$ & 0.0 & $99 \%$ & $\underline{\text { GU187652.1 }}$ \\
\hline Q & Leucogyrophana olivascens CFMR:HHB-11134 $18 \mathrm{~S}$ small subunit ribosomal RNA gene, partial sequence & 1290 & 1290 & $99 \%$ & 0.0 & $99 \%$ & $\underline{\text { GU187639.1 }}$ \\
\hline 0 & Leucogyrophana arizonica CFMR:RLG-9902 18S small subunit ribosomal RNA gene, partial sequence & 1290 & 1290 & $99 \%$ & 0.0 & $99 \%$ & $\underline{\text { GU187636.1 }}$ \\
\hline
\end{tabular}

Fig. 3. Full length sequence and homology search of BRM-13 (Gyrodontium sacchari). 
Akash, D. et al. / J. Appl. \& Nat. Sci. 9 (3): 1381 -1387 (2017)
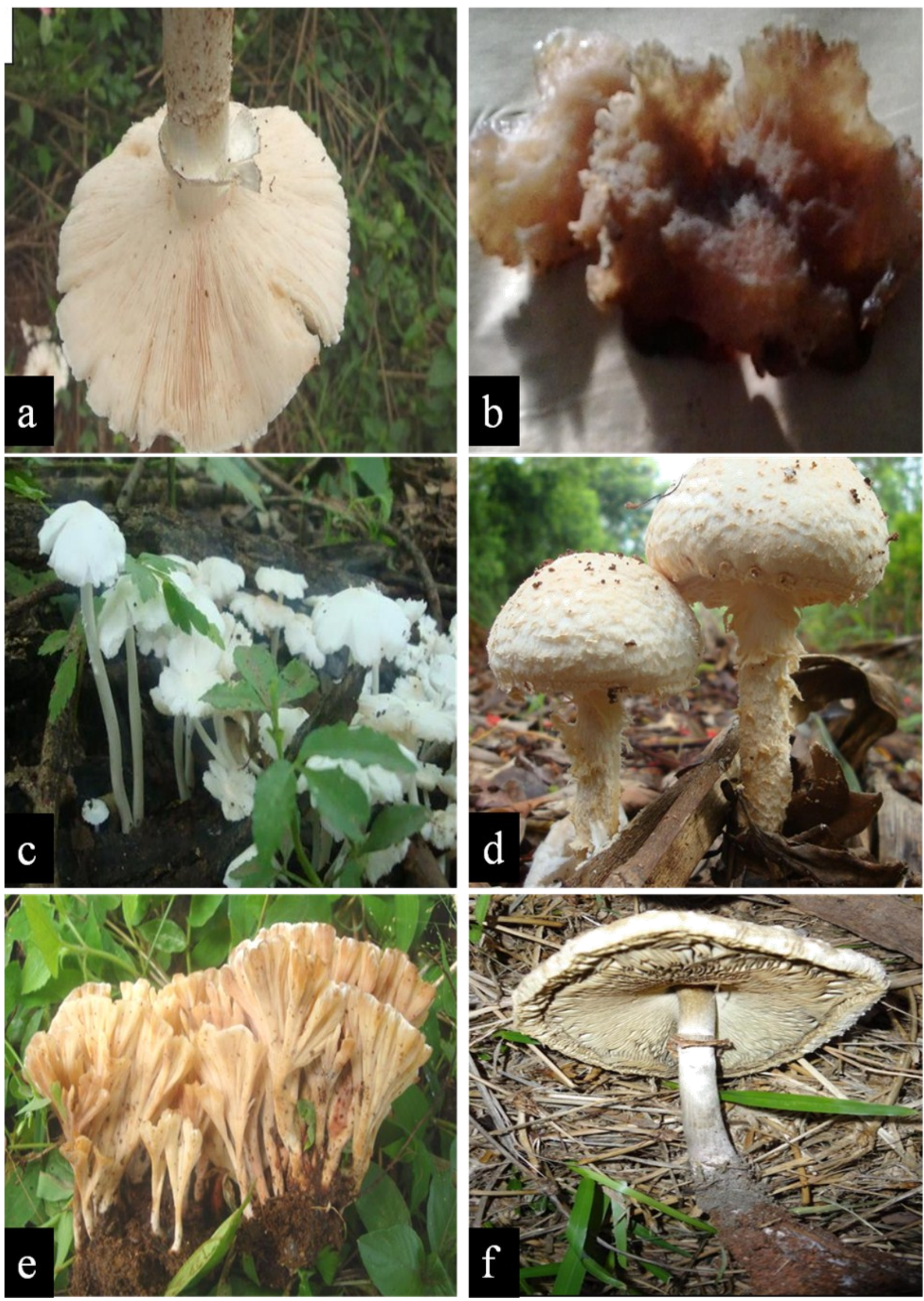
Akash, D. et al. / J. Appl. \& Nat. Sci9 (3): 1381 -1387 (2017)
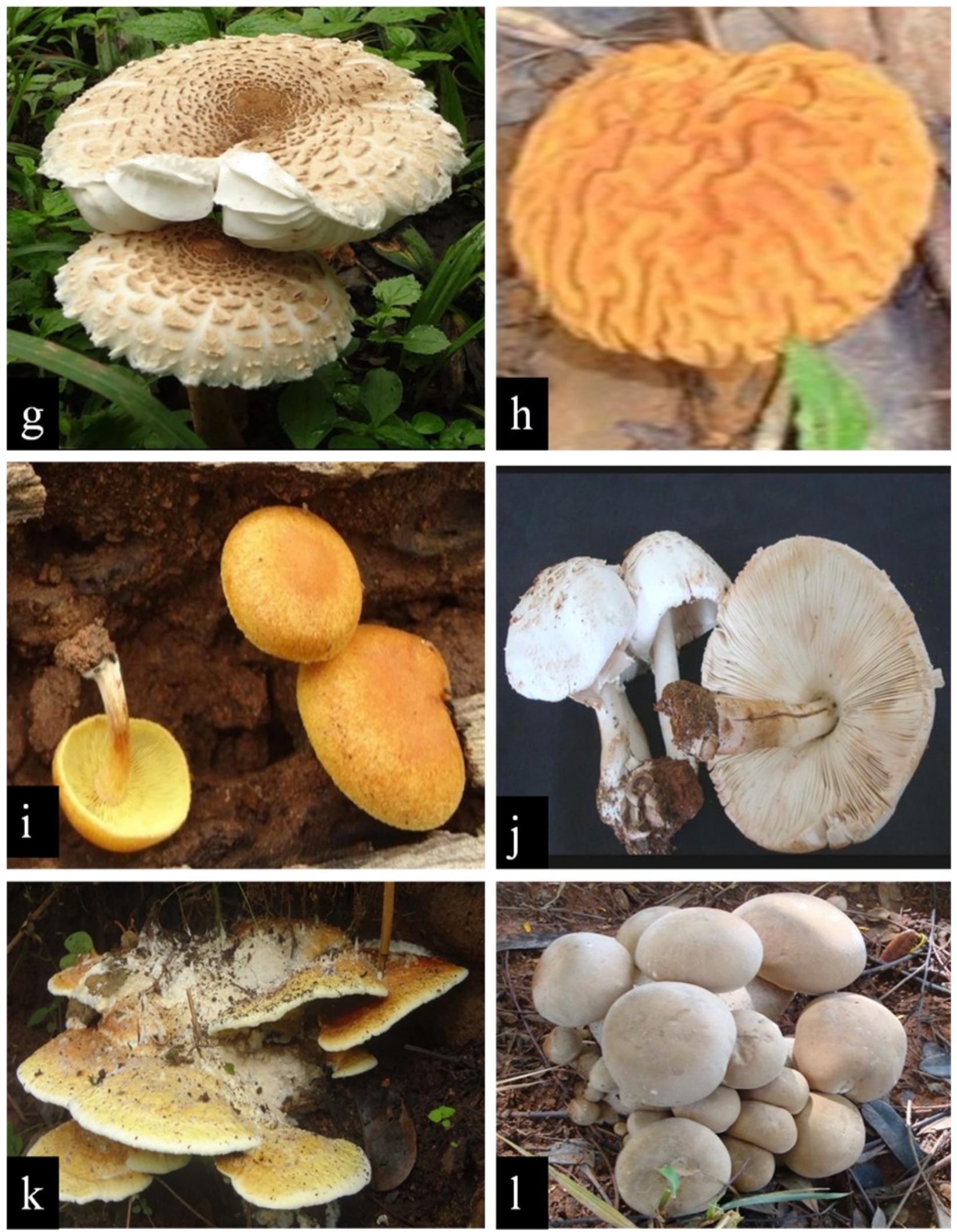

Fig. 4. (a)Termitomyces sp. (BRM-3), (b)Auricularia delicata (BRM-4), (c)Termitomycesmicrocarpus (BRM-5), (d) Amanita sp. (BRM-6), (e)Podoscypha petalodes (BRM-7), (f)Agaricaceae sp. (BRM-8), (g) Macrolepiota sp. (BRM-9), (h)Calvatiaholo thurioides (BRM-10), (i)Gymnopilus crociphyllus (BRM-11), (j)Coprinus comatus (BRM-12), (k)Gyrodontium sacchari (BRM-13), (l)Clitocybeaff.fellea (BRM-14). 
primer for all eukaryotic species (Rajaratnam and Thiagarajan, 2012). We identified 12 mushrooms by using ITS primers showed variation in the amplicon size (Table 2). Amplicon size of the ITS region varied from 542-822bp for different mushroom species in this study. This could be due to insertion, deletion, duplication and translocation. Further, it may also be due to species variation (Zhihongetal., 2003). Sudipet al. (2013) collected eight wild edible mushrooms from eastern Chota Nagpur plateau of West Bengal, India and was identified using ITS 1 and ITS 2 primers. The aligned sequence revealed identity of Amanita hemibafpha, Amanita sp., Astraeushygrometricus, Termitomycessp., Termitomyces sp., Volvariellavolvceae, Termitomyces sp.Thus, molecular identification has become faster and precise method of classification compared to classical taxonomy. However, molecular taxonomy will be blind without knowing morphological identity to mushroom hunter. Out of fourteen mushrooms collected in this survey, three mushrooms viz., Termitomyces sp.,Auricularia delicata, and Termitomyces microcarpus belonged to edible species and the $A$. delicate being a cultivable mushroom can be exploited for commercial production. The other species are good decomposers of organic matter.

\section{Conclusion}

The BR hills are the hot spot of biodiversity. Various flora and fauna including birds are documented by the Department of Ecology and Environment of Karnataka. This study adds the mushroom resources to the biodiversity. Further, the study revealed that the diversity of mushroom flora (edible, poisonous and medicinal species) which are of scientific importance besides for commercial exploitation.

\section{ACKNOWLEDGEMENTS}

Authors are grateful to the Department of Biotechnology, Govt. of India, New Delhi (Ac No. BT/INF/UAS Bangalore/2011) for financial support to carry out this research.

\section{REFERENCES}

Altschul, S. F., Gish, W., Lipman, W. W. (1990). Basic local alignment search tool.J. Mol. Boil.,215(3): 403- 410

Arora, D., (1986). Mushrooms Demystified: A comprehensive guide to the fleshy fungi.Ten Speed Press., Pp, 8-28
Bakshi B. K. (1971). Indianpolyporaceae. Indian Council of Medical Research (ICMR)., Pp, 232-246

Bhatt, R.P., Bhatt, V.K., and Gaur, R.D. (1995). Fleshy fungi of Garwahal Himalaya: The genousRussula. Indian Phytopath.,48(4): 402-411

Gireesha, J and Raju, N.S. (2013).Ethnobotanical study of medicinal plants in BR Hills region ofWestern Ghats, Karnataka, Asian J. PlantSci. Res., 3(5): 36-40

Hobbs, C. H. (1995). Medicinal mushrooms: an exploitation of tradition, healing and culture. Botanica press.Santacruz., Pp, 219-251

Madigan, M. T., Martinco, J. M., Dunlap, P. V. and Clark, D. P. (2009). Microbial evolution and systematics In: Biology of microorganisms. PearsonBenjamin cummings, Sanfranscisco., Pp,358-393

Meera, P. and Veena, S. S. (2012). Characterization and conservation of edible and medicinal mushrooms of Western Ghats of India. Indian. J. Trop. Biodiv., 20(1):37-44.

Oyetayo, V. O. (2012). Wild Termitomycesspecies collected from Ondo and Ekiti States are more related to African speciesas revealed by ITS region of rDNA. Sci. World J., 1:1-5.

Rajaratnam, S. and Thiagarajan, T. (2012).Molecular characterization of wild mushroom.Eur. J. Exptl. Biol., 2(2): 369373

Sambrook, J., Fritsch, E.F. and Maniatis, T. (1989).Molecular cloning:A laboratory manual. Cold Spring Harbor Laboratory press., $\mathrm{Pp}, 13-55$

Sreenivasan, U and Prashanth,N. (2005). Addtions to the avifauna of the BiligiriRangana Hills, Karnataka, Indian Birds., 1 (5): 103-104.

Sudip, K. D., Aninda, M., Animesh, K., Datta.,Sudha, G., Rita, P., Aditi., Sonali, S. and Priyanka, K. D. (2013). Nucleotide sequencing and identification of some wild mushrooms.The Scientific World J., 1: 7-10

Victor, Olusegun. AndOyetayo. (2012). Wild Termitomyces species collected from Ondo and Ekiti states are more related to African species as revealed by ITS region of $\mathrm{r}$ DNA. African J. Bitechnol., 10(14): 1-8.

Wasser, S. P. and Weis, A.L.(1999). General description of the most important medicinal higher Basidiomycetes mushrooms.Int. Med.Mush.,1: 351-370.

Gross, W., Heilmann, I., Lenze, D. and Schnarrenberger, C. (2001). Biogeography of the Cyanidiaceae (Rhodophyta) based on 18 S ribosomal RNA sequence data., Eur. J. Phycol., 36: 275-280.

Zhihong, W., Yoshihiko, T., Goran, B. and Xiaoru, W. (2003). 18S rRNA gene variation among common airborne fungi and development of specific oligonucleotide probes for the detection of fungal isolates. Appl. Environ.Microbiol., 69: 5389-5397. 